\title{
Effect of Selected Moisture Reference Year on the Durability Assessment of Wall Assemblies under Future Climates
}

\author{
Sahar Sahyoun ${ }^{1}$, Hua Ge ${ }^{2}$, Chetan Aggarwal $^{3}$, Maurice Defo ${ }^{4}$ and Travis Moore ${ }^{5}$ \\ ${ }^{1}$ Ph.D. Student, Concordia University, Montreal, Canada; s_sahyo@concordia.live.ca \\ ${ }^{2}$ Associate Professor, Concordia University, Montreal, Canada; hua.ge@concordia.ca \\ ${ }^{3}$ Ph.D. Student, Concordia University, Montreal, Canada; c_agga@encs.concordia.ca \\ ${ }^{4}$ Associate Research Officer, Construction Research Centre, National Research Council Canada, \\ Ottawa, Canada; Maurice.Defo@nrc-cnrc.gc.ca \\ ${ }^{5}$ Research Council Officer, Construction Research Centre, National Research Council Canada, \\ Ottawa, Canada; Travis.Moore@nrc-cnrc.gc.ca
}

\begin{abstract}
Hygrothermal simulations are commonly used to evaluate the moisture damage risk of building envelopes over the long-term. For such assessment to be accurate, a proper selection of representative climate data is required. A common method is the selection of a moisture reference year from a set of available long-term climate data. For instance, the IRC-led research consortium MEWS (Moisture Management of Exterior Wall Systems) developped the Moisture Index (MI) approach, which consists of a wetting and a drying function. Therefore, the reference year selection would be based on the MI ranking. ASHRAE 160 is adopting a procedure named "the severity index" for the selection of moisture reference year. Combining climate loads and durability criteria, this method allows to select more "severe" weather years, thus providing a more representative ranking of the weather data. The objective of this paper is two-fold. First, to compare the selection of the moisture reference year based on two different approaches for both historical and future climate loads. Second, the effect of chosen representative years is evaluated and compared to long-term simulation periods (of 31-years) based on the durability of building assemblies. The methodology includes hygrothermal simulations of two different types of wall assemblies located in three different Canadian cities under a changing climate. In general, higher mold index values were obtained by the long-term simulation and MRYs using Isev. Comparing the results of different models under future climates, the three methods were in good agreement, except for a brick wall facing WDR in Ottawa and Vancouver. This might be due to the Isev correlations were developed based on a north-facing stucco wall. In addition, for a north-facing wall, an extremely low mold index was predicted for Vancouver, compared to WDR direction. Thus, considering a north-facing wall as a criterion for performance evaluation might misrepresent the reality in some locations. Hence, both WDR and North orientations should be considered. A further study will be carried out to investigate the performance evaluation of Isev method for different types of wall systems and orientations.
\end{abstract}

Keywords: Moisture Reference Year, Durability, Wind-Driven Rain, Mold Index, Climate Change.

\section{Introduction}

With the increased concern of climate change, severe rainfall events are more likely to happen. Therefore, water penetration in wall assemblies, resulting from the coupled action of rain and wind, may cause moisture to accumulate in building envelopes which can lead to degradation 
of building materials; thereby, reducing their performance and service life. Heat, air and moisture (HAM) simulation tools are typically used to determine the risk to deterioration of buildings' elements. However, these tools neccessite the selection of representative climate data, as well as a good understanding of the moisture conditions, in order to provide an accurate assessessement (Delgado et al., 2012). Therefore, a moisture reference year is usually selected from existing long-term climate data to represent a climate that allows a correct evaluation of the moisture stress on the building envelope (Zhou et al., 2016).

Different methods were introduced in the past and have been used to define moisture reference years (Hagentoft and Harderup, 1993; Harderup, 1994; Geving, 1997; Kalamees and Vinha, 2004; and Zhou et al., 2016). The IRC-led research consortium MEWS (Moisture Management of Exterior Wall Systems) developped the Moisture Index (MI) approach, which includes wetting and drying indices (Cornick et al., 2003). The wetting index (WI) can be represented by the mean annual total horizontal rainfall or the annual wind-driven rain load. The drying index (DI) is based on the yearly evaporation potential - meaning the total hourly difference between the saturation vapor ratio and actual vapor ratio of the ambient air. Besides, ASHRAE (2010) has further developed MRY selection measures, combining climate loads and durability criteria to select more "severe" weather years, thus providing a more representative ranking of the weather data. This new approach - the Severity Index (Isev), consists of a simple equation that would be used to calculate the predicted damage function value for each year. Salonvaara et al. (2010) have demonstrated that Isev is the most reliable and the most accurate among all available methods in selecting the most severe years in terms of hygrothermal performance for climates

The objectives of this

on the moisture index

climate loads. The effect of representative

assemblies is evaluatdd under different moistu

thus made between the effect of selected representative years and the long-term simulations on

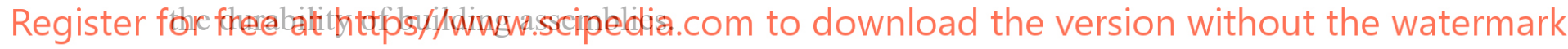

\section{Methods}

\subsection{Weather Data}

Weather data were provided by the National Research Council of Canada (NRC). A continuous time-series ${ }^{1}$ of hourly climate data was prepared for a baseline time-period spanning from 19862016 and a 31-year long future time-period selected for when projected global warming of $3.5^{\circ} \mathrm{C}$ is expected to be reached in the future (Gaur et al., 2019). According to projections from Environment and Climate Change Canada (2018), future projected data of a $3.5^{\circ} \mathrm{C}$ increase, will be reached between 2062-2092. Each data set includes 15 realizations; however, only the median realization based on MI was used.

\footnotetext{
${ }^{1}$ The full dataset can be accessed from: 10.17605/OSF.IO/UPFXJ.
} 


\subsubsection{Selection of Reference Years}

The selection of reference years was made with the intention to test wall assemblies under more representative design weather years in the selected timelines. Moisture Index (MI) and severity index (Isev) have been chosen as the indices for selecting the reference years. Both methods were used to select one (1) year as the reference year.

Following the previous work performed at NRC (Cornick et al., 2003), MI for every hour $\left(\mathrm{MI}_{\mathrm{h}}\right)$ was calculated as a function of hourly wetness $\left(\mathrm{WI}_{h}\right)$ and dryness $\left(\mathrm{DI}_{\mathrm{h}}\right)$ indices. $\mathrm{WI}_{\mathrm{h}}$ is calculated as normalized accumulated hourly rainfall. Dryness index $\left(\mathrm{DI}_{\mathrm{h}}\right)$ was calculated as a function of the difference between saturation vapor pressure and vapour pressure of the ambient air $\left(\Delta_{v p}\right)$. The saturation vapor pressure, $p_{v s}$, was calculated using Equation (1), retrieved from the ASHRAE Handbook of Fundamentals (ASHRAE, 2009).

$$
\ln \left(p_{w S}\right)= \begin{cases}\frac{C_{1}}{T}+C_{2}+C_{3} T+C_{4} T^{2}+C_{5} T^{3}+C_{6} T^{4}+C_{7} \ln (T) & \text { for } T<0 \\ \frac{C_{8}}{T}+C_{9}+C_{10} T+C_{11} T^{2}+C_{12} T^{3}+C_{13} \ln (T) & \text { for } T \geq 0\end{cases}
$$

Where, $\mathrm{C}_{1}=-5.6745359 \mathrm{E}+03 ; \mathrm{C}_{2}=6.392524 \mathrm{E}+00 ; \mathrm{C}_{3}=-9.6778430 \mathrm{E}-03 ; \mathrm{C}_{4}=6.2215701$ $\mathrm{E}-07 ; \mathrm{C}_{5}=-5.6745359 \mathrm{E}+03 ; \mathrm{C}_{6}=-9.4840240 \mathrm{E}-13 ; \mathrm{C}_{7}=4.163501 \mathrm{E}+00 ; \mathrm{C}_{8}=-5.8002206$ $\mathrm{E}+03 ; \mathrm{C}_{9}=1.3914993 \mathrm{E}+00 ; \mathrm{C}_{10}=-4.8640239 \mathrm{E}-02 ; \mathrm{C}_{11}=4.1764768 \mathrm{E}-05 ; \mathrm{C}_{12}=-1.4452093$ $\mathrm{E}-08 ; \mathrm{C}_{13}=6.5459673 \mathrm{E}+00$; and $\mathrm{T}$ denotes the ambient temperature (K).
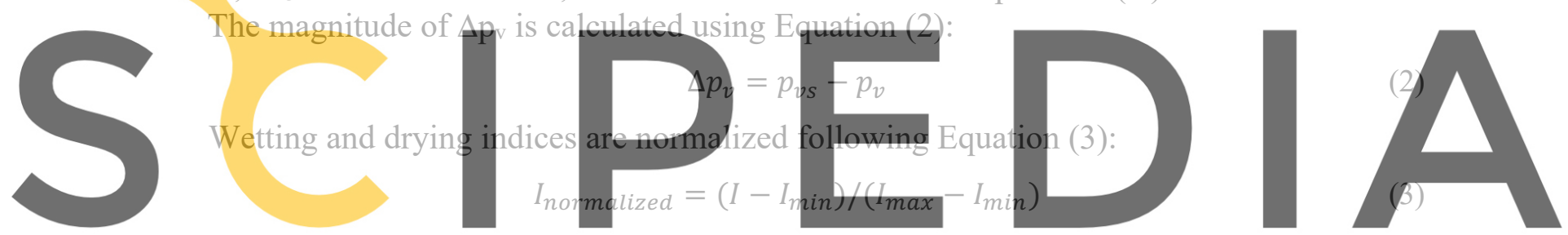

Normalized values of $\Delta \mathrm{p}_{\mathrm{v}}$ were used as $\mathrm{DI}_{\mathrm{h}}$ magnitudes. Wetting and drying were assumed

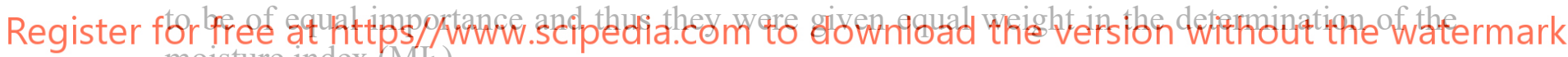
moisture index $\left(\mathrm{ML}_{\mathrm{h}}\right)$.

$$
M I_{h}=\sqrt{\left(1-D I_{h, n o r m}\right)^{2}+W I_{h, n o r m}}
$$

Based on ASHRAE (2010), the severity index (Isev) for each year is calculated according to Equation (5):

$$
\begin{aligned}
I_{s e v}=108307 & -241 . E_{v}-1391 . I_{c l}-312326 . \phi+183308 . r_{w d}+15.2 . p_{v} \\
& +27.3 . T^{2}+261079 . \phi^{2}-0.00972 . p_{v}^{2}
\end{aligned}
$$

Where, $E_{v}$ is the solar radiation $\left(\mathrm{W} / \mathrm{m}^{2}\right)$ incident on the wall; $\mathrm{I}_{\mathrm{cl}}$ is the cloud index $(0-8) ; \phi$ is the relative humidity; $r_{w d}$ is the wind-driven rain $\left(\mathrm{kg} / \mathrm{m}^{2} . \mathrm{h}\right)$ on the wall; $p_{\mathrm{v}}$ is vapor pressure $(\mathrm{Pa})$, and $\mathrm{T}$ is the ambient temperature $\left({ }^{\circ} \mathrm{C}\right)$. As specified by the method, Isev was calculated for the orientation receiving the least solar radiation (North). All the weather parameters were calculated in terms of annual average values for each year; using the number of hours during that year. 
Once both annual average MI and Isev values were available, the years comprising the chosen time-period were ranked in ascending order, and the year corresponding to the 97th percentile, (ranked second out of the 31 years) in each time-period was chosen as the MRY. Figure 1 shows the annual average values of MI and Isev at each location, for a wall facing North.
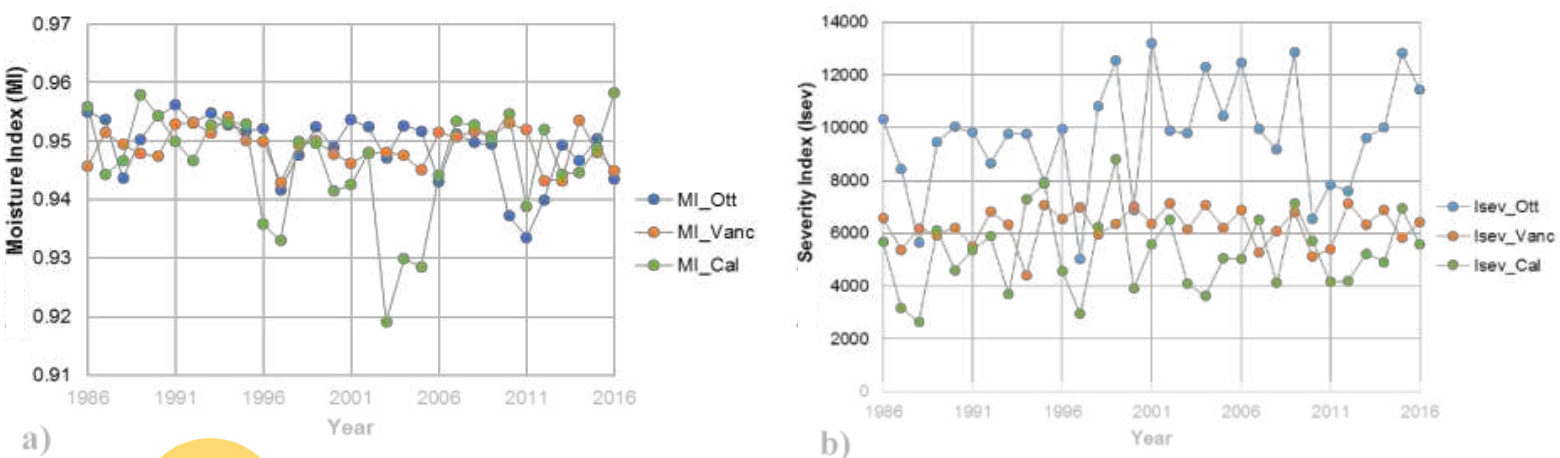

Figure 1. Comparison of annual moisture index MI (a) and Isev (b) in Ottawa (Ott), Vancouver (Vanc) and Calgary (Cal) for a North-facing wall based on historical data.

Table 1 summarizes the selected MRYs based on different locations under historical and future time-periods.
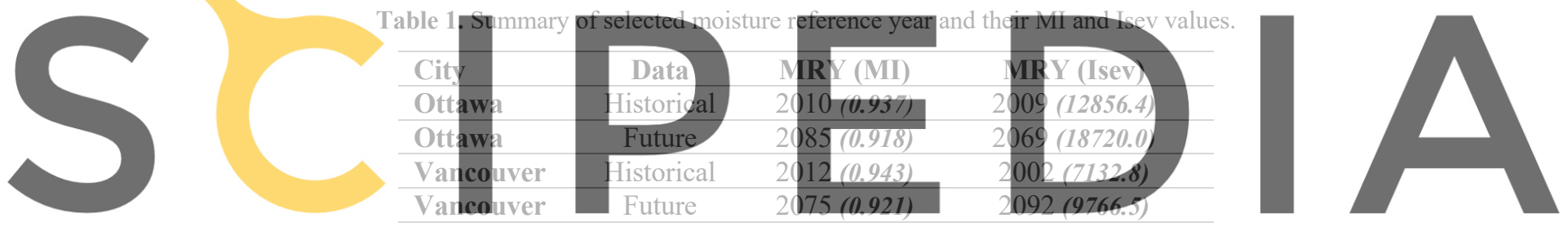

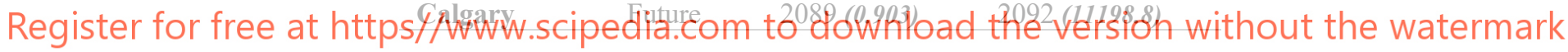

\subsection{Wall Assemblies}

Two (2) wood frame wall assemblies, typical of Canadian residential building practice, were selected for this study. They differ only in their cladding type: stucco $(19 \mathrm{~mm})$ and brick $(90$ $\mathrm{mm}$ ). A drainage cavity of $25 \mathrm{~mm}$ and $10 \mathrm{~mm}$ was designed for the brick and the stucco wall, respectively. Figure 2 shows the configuration of the wall assemblies.
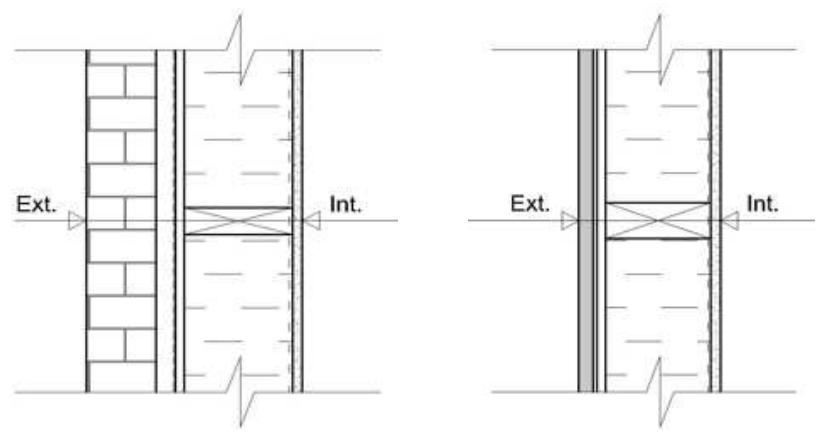
The general configuration inboard of the cladding consisted of:
- Paper-based sheathing membrane
$11 \mathrm{~mm}$ OSB sheathing Wood studs (38mm x $140 \mathrm{~mm})$ Polyethylene vapor barrier $12 \mathrm{~mm}$ Interior finish (gypsum + primer +latex)

Figure 2. Wall assemblies' configuration for brick (a) and stucco (b). 


\subsection{Wall Orientation}

This study was carried out for two wall orientations for each location: the orientation with the least annual solar radiation - meaning on a North-facing wall $(\mathrm{N})$, and the orientation with the highest amount of annual wind-driven rain, calculated according to ASHRAE (ANSI/ASHRAE, 2016). The critical orientation (WDR) is presented in Table 2 for each city.

Table 2. Characteristis and wall orientation for selected Canadian cities.

\begin{tabular}{lccccc}
\hline City & Lat. & Long. & $\begin{array}{c}\text { Climate } \\
\text { zone }\end{array}$ & $\begin{array}{c}\text { Time } \\
\text { zone }\end{array}$ & $\begin{array}{c}\text { Critical orientation } \\
\text { (WDR) }\end{array}$ \\
\hline Ottawa & $45.25^{\circ}$ & $75.42^{\circ}$ & 6 & -5 & $202.5^{\circ}(\mathrm{SSW})$ \\
\hline Vancouver & $49.28^{\circ}$ & $123.12^{\circ}$ & 5 & -8 & $157.5^{\circ}(\mathrm{SSE})$ \\
\hline Calgary & $51.05^{\circ}$ & $114.07^{\circ}$ & $7 \mathrm{~A}$ & -7 & $337.5^{\circ}(\mathrm{NNW})$ \\
\hline
\end{tabular}

\section{Boundary Conditions}

\subsubsection{Indoor Boundary Conditions}

The indoor temperature and relative humidity conditions were selected as constants and set to $21^{\circ} \mathrm{C}$ and $50 \%$, respectively. For the indoor vapour diffusion and the heat conduction, the transfer coefficients were assumed as $1.52 * 10^{-8} \mathrm{~s} / \mathrm{m}$ and $8 \mathrm{~W} / \mathrm{m}^{2} \mathrm{~K}$, respectively.

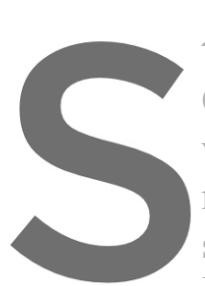

2.4.2 Outdoor Boundary Conditions

Outdoor boundary conditions include heat conduction, vapor

wave radiation and long wave radiation. To con

method was selected in

surface was set to 0.9 , whereas the convective

Equation (6):

$h_{c e}=4+4 . v$

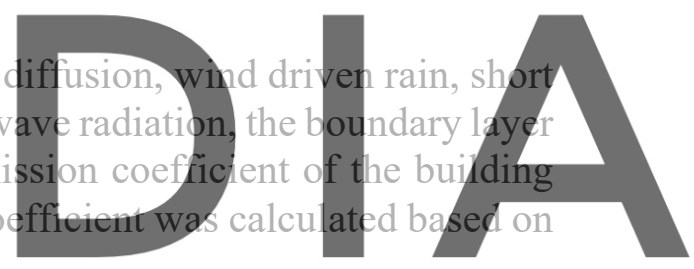

longwave ve emissi

Where, $v$ is the wind speed. The reflection coefficient of the surrounding ground (albedo) was 0.2 and the absorptance coefficient of the cladding surface was equal to 0.6 for brick and 0.3 for stucco.

\subsubsection{Wind-Driven Rain}

WDR was calculated using the ASHRAE method (ANSI/ASHRAE, 2016) for a 3.5 storey building located in the suburban area. Assuming a medium exposure factor, the rain exposure factor $\left(\mathrm{F}_{\mathrm{E}}\right)$ and the rain deposition factor $\left(\mathrm{F}_{\mathrm{D}}\right)$ were set to 1.0 and 0.5 , respectively.

\subsection{Initial Conditions}

The wall was first condionned with suitable climate and simulations were performed for a period of 7 successive years using the average year (based on MI ranking). Once a steady cyclical pattern was observed at the exterior side of OSB, the average temperature and relative humidity for each material were exported and used as initial conditions. 


\subsection{Performance Attributes for Assessing Wall Performance}

One important performance attribute for wood-based building elements is the resistance to mould growth. Under favourable conditions of temperature and relative humidity, mould fungi can grow on building component surfaces and this is often regarded as problematic in respect to indoor air quality (Wang et al., 2018). OSB is susceptible to mould growth if subjected to these favourable conditions. The outward layer of the OSB sheathing $(\sim 0.1 \mathrm{~mm})$ was selected as the critical location for this study. The mould growth index was calculated using Viitanen's model implemented in DELPHIN (Viitanen et al., 2000).

Several trials were made to select the air change per hour $(\mathrm{ACH})$ value in drainage cavities, in a way that the mold index stabilizes around a value of 3 during the long-term simulation. Different values of $\mathrm{ACH}$ were set based on the cladding type and the location (Table 3 ).

Table 3. ACH values selected according to different cladding and locations for North and WDR orientations.

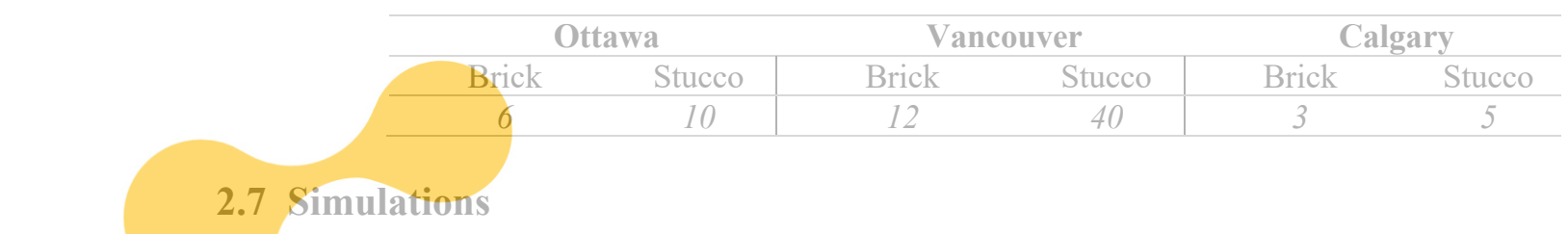

Manual discretization was adopted; for the sheathing membrane and the vapour barrier, an equidistant mesh of 3 elements was assumed. Other materials were divided into three sections

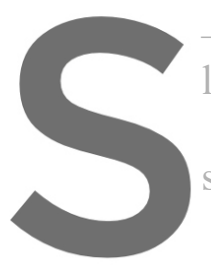
- with first and last sections of equal thicknes
latter, while an equidistant mesh was opted for
A moisture source of $1 \%$ of the WDR was a
sheathing membrane - on the first layer of the
Each selected MRY was repeated 5 times;

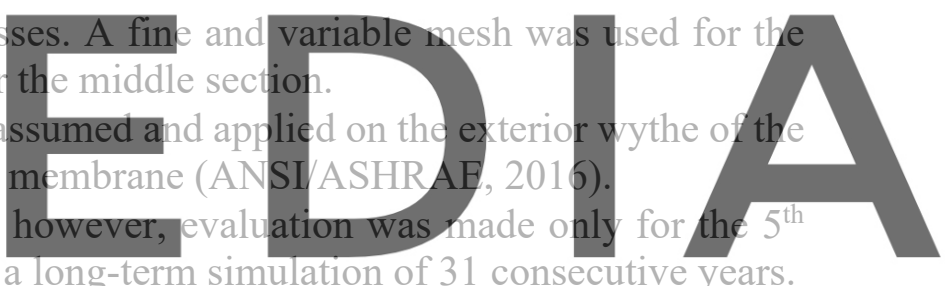

year. These results were compared to those of a long-term simulation of 31 consecutive years

Register fogr fresuat httpstbunwwscipedia.com to download the version without the watermark

Figure 3 shows the predicted risk to mold growth on the outer layer of OSB for different types of walls under different climate loads, which were selected based on different reference year methods, i.e., MI and Isev. Results are compared to that of a long-term simulation (31-Y) in three Canadian cities. The 31-Y results were selected for the year having the second highest mold index value. In general, the differences amongst the mold indices vary with the cladding type, the location (climate) and the wall orientation. Comparing the impact of MRY selection method, in most of the cases, the mold index is found higher based on Isev selection - meaning that MRYs selected according to Isev predicted a higher damage risk than years selected based on MI. Moreover, results of the 31-Y seem more in accordance with Isev.

For a brick wall (Figure 3a), mold index values are found higher for Isev and 31-Y, and in some events, especially in Ottawa, results for Isev seem to overestimate the risk. This may be due to the difference between the MRYs selected by Isev and the years corresponding to the $2^{\text {nd }}$ highest mold index value for the 31-Y. It seems that the climate selected based on Isev is more favorable for mold growth. However, for stucco (Figure 3b), results are found to be more consistent; with 31-Y estimating highest mold index values. Moreover, the difference between the methods had a greater impact on the wall performance. For instance, both $31-\mathrm{Y}$ and Isev 
estimated a considerable risk to mold growth compared to results given by MI. For a wall facing North in Ottawa, a maximum mold index value of 4.5 and 5 was attained for historical and future climate, respectively for 31-Y. Using the Isev method, values of 4 and 4.8 were reached. However, using MI, maximum values of 1 and 2.8 were attained for different climates. Likewise in Calgary, the difference in mold prediction risk varried considerably between the methods.

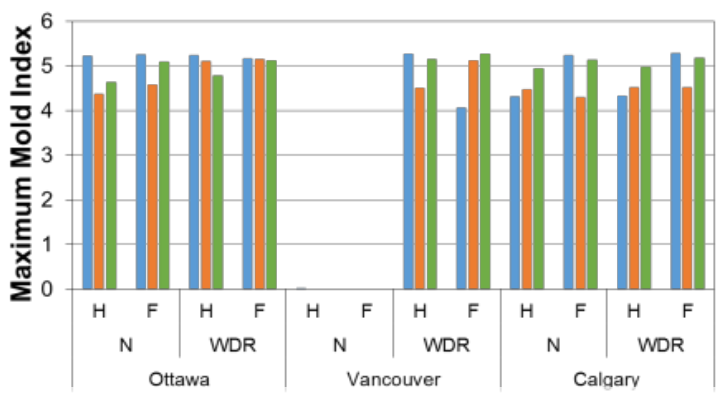

a) Brick

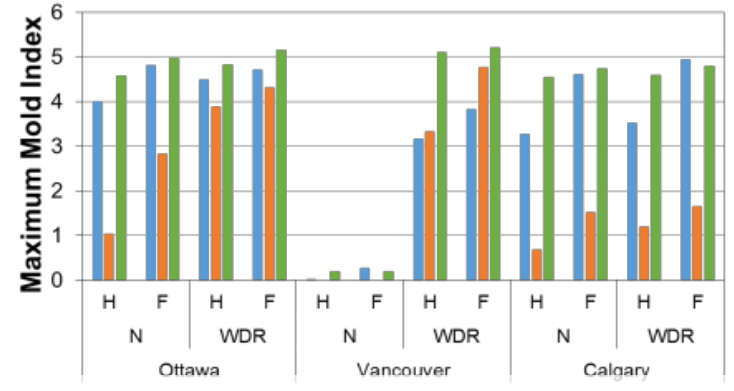

b) Stucco

Figure 3. Summary of maximum mold index predicted through a long-term study (31-Y) and using MRYs given by Isev and MI for historical (H) and future (F) climatic loads, for walls facing North (N) and WDR.

It can be also observed that in Vancouver, when the wall is facing North, all three methods predicted no risk of mould growth. This can be explained due to a low amount of WDR impiging on a North facing wall in that city. It is also important to note the effect of the selection

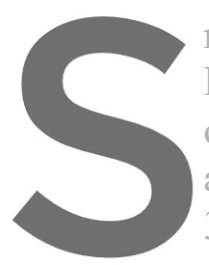
method on the assessine Mold index values incret of a brick wall facing to a slight decrease in mo 3a). The severity index ent of the climato chang
ward the WDR in Ottaw
index for Ottawa but a
calculated was based on e impact on the
ate loads in most
a considerable
$n$ the correlations
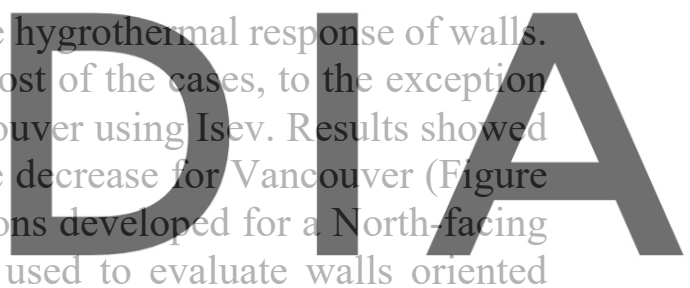

orientation. Discrepancy may exist when the same year is used to evaluate walls oriented

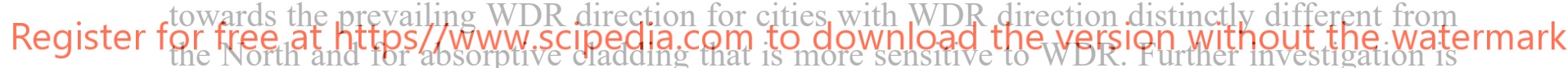
required on the aspect of wall orientation. The impact of climate change is more consistent for the stucco wall (Figure 3b), where the difference of mold index is increased by up to 2 indices (for the case of a north oriented wall in Ottawa and Calgary).

\section{Conclusions}

In this study, the effect of selecting MRYs on the expected long-term moisture performance and durability is investigated from results derived from hygrothermal simulations of typical wood-frame wall assemblies in three Canadian cities. The durability performance was assessed based on the potential to mold growth on the OSB sheathing incorporated in stucco and brick veneer clad wall assemblies. Results showed that the use of different climate load indices (i.e. MI or Isev) can lead to different conclusions on the moisture performance of these types of wood-frame walls. In general, higher mold index values were obtained from the long-term simulation and MRYs using Isev for both walls in all three locations. Comparing the results of different models under future climates, the three methods were in good agreement, except for a brick wall facing WDR in Ottawa and Vancouver. This might be due to the fact that the Isev correlations were developed based on a North-facing stucco wall (ASHRAE, 2010). In addition, 
for a north-facing wall, an extremely low mold index was predicted for Vancouver, compared to the value of the mould index as was attained from simulations when the prevailing WDR direction was used as input to the climate loads. Thus, considering a North-facing wall as a criterion for performance evaluation might misrepresent the actual moisture behavior in some locations. Hence, for each location, both WDR and North orientations should be considered. A further study will be carried out to investigate the performance evaluation of Isev method for different types of wall systems and orientations.

\section{ORCID}

Sahar Sahyoun: https://orcid.org/0000-0001-5131-6134

Hua Ge: http://orcid.org/0000-0003-1368-4301

Chetan Aggarwal: http://orcid.org/0000-0002-7224-9740

Maurice Defo: http://orcid.org/0000-0001-9212-6599

Travis Moore: http://orcid.org/0000-0002-4920-9193

References

ANSI/ASHRAE. (2016). Criteria for Moisture Control Design Analysis in Buildings. Atlanta.

ASHRAE. (2010). Environmental weather loads for hygro- thermal analysis and design of buildings. RP-1325, American Society of Heating, Refrigerating and Air- Conditioning Engineers, Inc. Atlanta.

ASHRAE. (2009). ASHRAE handbook: Fundamentals. Atlanta.

Cornick, S., Djebbar, R. and Dalgliesh A.W. (2003). Selecting moisture reference years using a Moisture Index approach. Building and Environment, 38(12), 1367-1379.

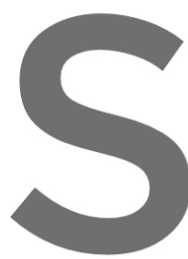

Delgado, J.M., Barreira, H., applied to building ph

Environment and Climate $\mathrm{C}$ Council and Environm

Gaur, A., Lacasse, M. and A Simulations Under Prdjer
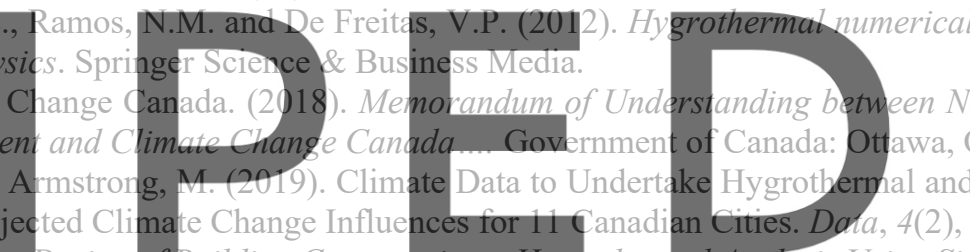

Geving, S. (1997). Moisture Design of Building Constru Part I and II, PhD thesis, Norwegian University of Science and Technology.

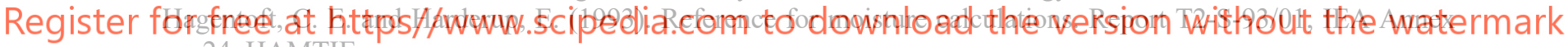
24, HAMTIE.

Harderup, E. (1994). Durability reference year: Using the $\pi$-factor method to find the DRY for three locations in Sweden. Report T2-S-94/01, IEA Annex 24, HAMTIE.

Kalamees, T. and Vinha, J. (2004). Estonian climate analysis for selecting moisture reference years for hygrothermal calculations. Journal of Thermal Envelope and Building Science 27:199-220.

Salonvaara, M., Sedlbauer, K., Holm, A. and Pazera, M. (2010). Effect of selected weather year for hygrothermal analyses. Proceedings of thermal performance of the exterior envelopes of whole buildings XI. ASHRAE.

Viitanen, H., Hanhijärvi, A., Hukka, A. and Koskela, K. (2000). Modelling mould growth and decay damages. Healthy Buildings, 341-346.

Wang, J., Stirling, R., Morris, P., Taylor, A., Lloyd, J. and al. (2018). Durability of mass timber structures: A review of the biological risks. Wood and Fiber Science 50,(Special Issue), 110-127.

Zhou, X., Derome, D. and Carmeliet, J. (2016). A new procedure for selecting moisture reference years for hygrothermal simulations. Bauphysik, 38, 361-365. 